\title{
$\gamma \delta$ T cell-mediated immune responses in disease and therapy
}

\section{T. Sree Latha ${ }^{1}$, Madhava C. Reddy ${ }^{2}$, Prasad V. R. Durbaka ${ }^{3}$, Aparna Rachamallu ${ }^{4,5}$, Reddanna Pallu ${ }^{4,5}$ and Dakshayani Lomada ${ }^{*}$ *}

1 Department of Genetics and Genomics, Yogi Vemana University, Kadapa, India

${ }^{2}$ Department of Biotechnology and Bioinformatics, Yogi Vemana University, Kadapa, India

${ }^{3}$ Department of Microbiology, Yogi Vemana University, Kadapa, India

${ }^{4}$ Department of Animal Biology, University of Hyderabad, Hyderabad, India

${ }^{5}$ National Institute of Animal Biotechnology (NIAB), Hyderabad, India

\section{Edited by:}

Julie Dechanet-Merville, Centre National de la Recherche Scientifique (CNRS), France

\section{Reviewed by:}

David Escors, University College London, UK

David Vermijlen, Université Libre de Bruxelles (ULB), Belgium

*Correspondence:

Dakshayani Lomada, Department of Genetics and Genomics, Room \# 124, Sir CV Raman Science Complex, Yogi Vemana University, Kadapa, AP 516003, India

e-mail:dlomada@yahoo.com, dlomada@

yogivemanauniversity.ac.in
The role of $\gamma \delta$ T cells in immunotherapy has gained specific importance in the recent years because of their prominent function involving directly or indirectly in the rehabilitation of the diseases. $\gamma \delta$ T cells represent a minor population of T cells that express a distinct T cell receptor (TCR) composed of $\gamma \delta$ chains instead of $\alpha \beta$ chains. Unlike $\alpha \beta$ T cells, $\gamma \delta$ T cells display a restricted TCR repertoire and recognize mostly unknown non-peptide antigens. $\gamma \delta T$ cells act as a link between innate and adaptive immunity, because they lack precise major histocompatibility complex $(\mathrm{MHC})$ restriction and seize the ability to recognize ligands that are generated during affliction. Skin epidermal $\gamma \delta$ T cells recognize antigen expressed by damaged or stressed keratinocytes and play an indispensable role in tissue homeostasis and repair through secretion of distinct growth factors. $\gamma \delta \mathrm{T}$ cell based immunotherapy strategies possess great prominence in the treatment because of the property of their MHC-independent cytotoxicity, copious amount of cytokine release, and a immediate response in infections. Understanding the role of $\gamma \delta \mathrm{T}$ cells in pathogenic infections, wound healing, autoimmune diseases, and cancer might provide knowledge for the successful treatment of these diseases using $\gamma \delta$ T cell based immunotherapy. Enhancing the human $\vee \gamma 9 V 82 T$ cells functions by administration of aminobisphosphonates like zoledronate, pamidronate, and bromohydrin pyrophosphate along with cytokines and monoclonal antibodies shows a hopeful approach for treatment of tumors and infections. The current review summarizes the role of $\gamma \delta$ T cells in various human diseases and immunotherapeutic approaches using $\gamma \delta T$ cells.

Keywords: $\gamma \delta \mathrm{T}$ cells, pathogenic infections, cancer, autoimmunity, wound healing, immunotherapy

\section{INTRODUCTION}

$\mathrm{T}$ cells are the principal lymphocytes that play a vital role in cellmediated immune responses. Majority of the T cells are $\alpha \beta$ T cells with $\alpha$ and $\beta$ chains and a minor population of $\gamma \delta \mathrm{T}$ cells do exist that play a pivotal role in the host defense system (1). $\gamma \delta \mathrm{T}$ cells are located in peripheral blood (PB), intestine, skin, spleen, and lymph nodes where they were found to act as interface for the cross talk between innate and cell-mediated immune cells (2). The functional development of $\gamma \delta \mathrm{T}$ cells is initiated much earlier than the development of $\alpha \beta$ T cells in embryogenesis, where $\gamma \delta \mathrm{T}$ cell Receptor (TCR) gene rearrangements were detected in the fetal thymus by "day 14" of embryogenesis (E14). The earliest murine $\gamma \delta \mathrm{T}$ cell "wave" expresses $\mathrm{V} \gamma 3 \mathrm{~V} \delta 1$ and gives rise to skin dendritic epidermal $\gamma \delta$ T cells (DETC). Later, vaginal and gut intra-epithelial $\gamma \delta \mathrm{T}$ lymphocytes (IEL) and immune organ $\gamma \delta \mathrm{T}$ cells were developed (3). V $\gamma 3 \mathrm{~V} \delta 1$ DETCs are exclusively generated in the fetal thymus, migrate to epidermal epithelia, expand locally and are maintained throughout the life of an individual (4). $\gamma \delta \mathrm{T}$ cells express TCR molecule on their cell surface, but there are only a few variable genes available to construct $\mathrm{V} \gamma / \mathrm{V} \delta$ TCR proteins. In addition, the usage of the $V \gamma / \mathrm{V} \delta$ genes is not random but appears to be dictated by the localization of $\gamma \delta$ T cells (5). Hence $\gamma \delta$ T cells are well engaged in newborns to contribute to immune-protection and immune-regulation $(6,7)$.

$\gamma \delta$ TCR recognize non-peptide antigens like glycerolipids and other small molecules, polypeptides that are soluble or membrane anchored, and cross linked to major histocompatibility complex (MHC) molecules or MHC-like molecules in an antigen-independent manner (8). Human $\mathrm{V} \gamma 9 \mathrm{~V} \delta 2$ (also known as $\mathrm{V} \gamma 2 \mathrm{~V} \delta 2) \mathrm{T}$ cells can be activated by metabolites from isoprenoid synthetic pathway. These include (E)-4-hydroxy-3-methyl-but-2enyl pyrophosphate (HMBPP), exogenous prenyl pyrophosphate from bacteria and parasitic protozoa and isopentenyl pyrophosphate (IPP), and endogenous prenyl pyrophosphate deriving from mevalonate pathway that operates in human. Aminobisphosphonates may activate $\mathrm{V} \gamma 9 \mathrm{~V} \delta 2 \mathrm{~T}$ cells by inhibiting the key enzyme farnesyl pyrophosphate synthase of mevalonate pathway in certain tumors leads to upregulating the endogenous pool of IPP (9). Vavassori et al. identified butyrophilin BTN3A1 molecule, which is involved in the presentation of phosphorylated antigens to 
V $\gamma 9$ V 82 T cells (10). Recently, Sandstrom et al. demonstrated that intracellular B30.2 domain of butyrophilin 3A1 (BTN3 A1) protein binds phosphoantigens ( $\mathrm{pAg}$ ) to mediate activation of human V $\gamma 9 \mathrm{~V} \delta 2 \mathrm{~T}$ cells. This intracellular B30.2 domain of BTN3A1 directly binds pAg through a positively charged surface pocket and charge reversal of pocket residues abrogates binding and activation of $\mathrm{V} \gamma 9 \mathrm{~V} \delta 2 \mathrm{~T}$ cells (11). Furthermore, Uldrich et al. reported that CD1d presents lipid-based antigens to human $\mathrm{V} \delta 1^{+}$ $\gamma \delta \mathrm{T}$ cells (12). $\gamma \delta \mathrm{T}$ cells use both the TCR and also additional activating receptors like natural killer $(\mathrm{NK})$ cell activating receptor (NKG2D), toll like receptor (TLR), and NOTCH signaling to respond to stress induced ligands and infection (13). Activated $\gamma \delta$ T cells promote the anti-infection capabilities of resident macrophages, NK cells, and also enhance the maturation of dendritic cells (DCs). Besides that, they secrete cytokines and chemokines to recruit pro-inflammatory neutrophils to accelerate the elimination of pathogens and the repair of damaged tissues. Neutrophils in turn suppress the $\gamma \delta \mathrm{T}$ cells activation to reduce the inflammation when the infection has been resolved (14). In addition, $\gamma \delta \mathrm{T}$ cells in the skin produce keratinocyte growth factor (KGF), important cytokine for wound repair, and epithelial cell regeneration. It has been demonstrated that the human $\gamma \delta$ $\mathrm{T}$ cells activation and expansion can be controlled by forkhead box P3 (FOXP3) expressing regulatory T cells (Tregs), programed death-1 (PD-1), and cytotoxic T lymphocyte antigen (CTLA)-4 both in vivo and in vitro (15).

$\gamma \delta \mathrm{T}$ cells bridge innate and adaptive immunity and play a protective role in immune-surveillance. Effector $\gamma \delta \mathrm{T}$ cells produce interferon (IFN) $-\gamma$, tumor necrosis factor (TNF)- $\alpha$, which enhance cell-mediated immune response and interleukin (IL)-17 that plays a vital role in early neutrophil mediated response. In addition, cytotoxic components such as perforin, granzymes secreted by these cells ultimately cause direct or indirect effect of cytotoxicity against infected cells (16). They provide a wide range of defense mechanisms against microorganisms such as viruses, bacteria, protozoa, and diseases like cancer and also in healing of wounds and burns. In addition, $\gamma \delta \mathrm{T}$ cells also play a role in autoimmune diseases such as rheumatoid arthritis (RA) and systemic lupus erythematosus (SLE) through their antigen-presenting capacity, release of pro-inflammatory cytokines, immunomodulatory properties, interaction with Tregs, and promotion of antibody production (17). Pantelyushin et al. reported that apart from retinoid-related orphan receptor gamma-t $\left(\mathrm{ROR} \gamma \mathrm{t}^{+}\right)$innate lymphocytes, $\gamma \delta \mathrm{T}$ cells also produce cytokines like IL-17A, IL-17F, and IL-22 that are essential and enough for psoriatic plaque formation in a disease model that closely resembles human psoriatic plaque formation (18). Current review exclusively focuses on the role $\gamma \delta \mathrm{T}$ cells in specific pathogenic infections, anti-tumor activity, healing of wounds and burns, autoimmune diseases, and few insights on their immunotherapy.

\section{PATHOGENIC INFECTIONS \\ TUBERCULOSIS}

Tuberculosis caused by Mycobacterium tuberculosis (Mtb) is considered to be one of the serious infectious disease worldwide causing 1.7 million deaths every year. Around 30\% of the world's population is affected by M. tuberculosis and approximately 100 million people died due to tuberculosis (TB) over the last century (19). Hence, there is an urgent need to find out the host factors that delineate the individuals susceptible to TB. pAg such IPP and HMBPP are the key ligands that activate $V \gamma 9 \mathrm{~V} \delta 2 \mathrm{~T}$ cells. HMBPP is nearly 1000 -fold more effective than IPP for the in vitro activation of $\mathrm{V} \gamma 9 \mathrm{~V} \delta 2 \mathrm{~T}$ cells (20). Mtb produces HMBPP, which is recognized by $\mathrm{V} \gamma 9 \mathrm{~V} \delta 2 \mathrm{TCR}$ and drives the activation of $\mathrm{V} \gamma 9 \mathrm{~V} \delta 2 \mathrm{~T}$ cells (21). Effector $\mathrm{V} \gamma 9 \mathrm{~V} \delta 2 \mathrm{~T}$ cells are shown to participate in the antiTB immune response by production of various cytokines (Th1, Th2, and Th17) and also activation of other immune cells such as $\mathrm{CD}^{+}$and $\mathrm{CD}^{+} \mathrm{T}$ cells, B cells, DCs, and macrophages (22). The in vivo studies have demonstrated that the major expansion of $\mathrm{V} \gamma 9 \mathrm{~V} \delta 2 \mathrm{~T}$ cells in macaques is induced only by HMBPP plus IL-2 co-treatment, but not IL-2 or HMBPP alone (23) although IL2 treatment of macaques expands CD $4{ }^{+} \mathrm{CD} 25^{+}$Foxp $3^{+}$Treg cells (24). In a primate model for $\mathrm{TB}, \gamma \delta \mathrm{T}$ cells produce IL-22 initially, which can be down regulated by HMBPP. There are various subsets of $\gamma \delta$ T cells, which are self regulative, and HMBPP treatment during early stages of infection might be helpful in evading Mtb (25). Peng et al. showed that upon stimulation with Mtb heat treated antigen (Mtb-HAg), levels of IFN $-\gamma$ producing $\mathrm{V} \gamma 9 \mathrm{~V} \delta 2$ $\mathrm{T}$ cells increased in number and were the main source of IL-17 (26). This led to the increased recruitment of phagocytic cells to the infected site and formation of granulomas in pulmonary TB. This reaction was antigen specific, because immunizing the same host once again with Mtb-HAg has led to faster reactivation of $\mathrm{V} \gamma 9 \mathrm{~V} \delta 2 \mathrm{~T}$ cells. Thus, stimulation of $\mathrm{V} \gamma 9 \mathrm{~V} \delta 2 \mathrm{~T}$ cells with pyrophosphates like IPP and HMBPP might represent a novel vaccine strategy to identify the key effector pathways of Mycobacteria stimulated $\mathrm{V} \gamma 9 \mathrm{~V} \delta 2 \mathrm{~T}$ cells that potentially act to inhibit the intracellular growth of Mycobacteria. In addition to that, human $\mathrm{V} \gamma 9 \mathrm{~V} \delta 2 \mathrm{~T}$ cells can recognizes many pathogen antigens and show rapid immune responses during infections including $E$. coli infections, salmonellosis, brucellosis, leprosy, tularemia, legionellosis, and listeriosis (27).

Bovine TB is caused by Mycobacterium bovis is a major zoonotic problem in United Kingdom and developing countries. $\gamma \delta \mathrm{T}$ cells show a major immunological response against $M$. bovis infection. Workshop cluster 1 (WC1) molecule expressed on $\mathrm{V} \gamma 9 \mathrm{~V} \delta 2$ $\mathrm{T}$ cells is involved in the antigen recognition including heatshock proteins, phospholipids derived from Mycobacteria, and other non-peptide antigens. $\mathrm{WC1}^{+} \gamma \delta \mathrm{T}$ cells are important in the development of granulomas during $M$. bovis infection by upregulating IFN- $\gamma$, IL-12, IL-18, MHC II, CD80/86, CD40, and adhesion molecules (22).

\section{MALARIA}

Malaria is a mosquito borne infectious disease caused by parasitic protozoan Plasmodium falciparum in humans and other animals. The WHO report 2013, has an estimate of 207 million cases of malaria with approximately 0.627 million deaths and 3.4 billion people prone to the risk of malaria (28). The information about the in vivo activation and anti-plasmodial action of the $\mathrm{V} \gamma 9 \mathrm{~V} \delta 2$ $\mathrm{T}$ cells is indistinct and it is important to understand the mechanisms of early control of the parasite multiplication and parasite density. It has been shown that elevated levels of $\gamma \delta \mathrm{T}$ cells in PB and spleen occur during acute plasmodium infection (29). $\gamma \delta \mathrm{T}$ 
cell-deficient [TCR $\delta$-knockout $(\mathrm{KO})]$ mice were unable to clear the infected red blood cells, showed high parasitemia and eventually died (30). Therefore, $\gamma \delta \mathrm{T}$ cells have the potential to react with malaria antigens rather than the $\alpha \beta \mathrm{T}$ cells or by NK cells (31). $\mathrm{V} \gamma 9 \mathrm{~V} \delta 2$ TCR recognizes schizont associated antigen (SAA) and HMBPP, are the antigens of $P$. falciparum result in the activation of $\mathrm{V} \gamma 9 \mathrm{~V} \delta 2 \mathrm{~T}$ cells $(31,32)$. Activated $\gamma \delta \mathrm{T}$ cells produce huge amount of IFN- $\gamma$ in presence of activated monocyte cytokines IL-10, IL-2, and IL-1 $\beta$. TLR-sensitized DCs express enhanced co-stimulatory factors on their surface and induce high levels of IFN- $\gamma$ production by human $\mathrm{V} \gamma 9 \mathrm{~V} \delta 2 \mathrm{~T}$ cells (33). The CD40 ligand on $\gamma \delta \mathrm{T}$ cells is ligated with CD40 on DCs and this signaling synergistically enhances the uptake of plasmodium antigens via DCs by increasing the production of IL-12 (30). Previous reports suggest that the number of polyclonally activated $\mathrm{V} \delta 2^{+} \mathrm{T}$ cells increase in $\mathrm{PB}$ during the acute phase of $P$. falciparum in malaria. In addition, in vitro activated $\mathrm{V} \gamma 9 \mathrm{~V} \delta 2 \mathrm{~T}$ cells express granzyme- $\mathrm{A}$ and $\mathrm{B}$, perforin, Fas/Fas ligand (FasL) and granulysin to kill the asexual stages of $P$. falciparum in the blood as well as inhibit the growth of intra erythrocytic stages (34). The P.falciparum was also known to be inhibited by human $\mathrm{V} \gamma 9 \mathrm{~V} \delta 2 \mathrm{~T}$ cells in vitro. The targets recognized by $\mathrm{V} \gamma 9 \mathrm{~V} \delta 2 \mathrm{~T}$ cells are extracellular merozoites of the host erythrocytes and this exclusively requires the contact between $\gamma \delta \mathrm{T}$ cells and the merozoites (35). Both the blood stages of intra erythrocytic parasite and extracellular merozoites themselves activates the V $\gamma 9 \mathrm{~V} \delta 2 \mathrm{~T}$ cells resulting in their degranulation by granulysin, but not by perforin (36). Teirlinck et al. reported that $\mathrm{V} \gamma 9 \mathrm{~V} \delta 2 \mathrm{~T}$ cells have the ability to develop effector memory cells after infection with P. falciparum (37) and this feature might be helpful in the development of novel cell based malaria vaccine.

\section{ACQUIRED IMMUNODEFICIENCY SYNDROME}

Acquired immunodeficiency syndrome is caused by human immunodeficiency virus (HIV) and is one of the greatest health crises ever faced by the global community. It has been demonstrated that circulating $\mathrm{V} \gamma 9 \mathrm{~V} \delta 2 \mathrm{~T}$ cells exhibit anti-HIV role by secreting chemokines for HIV entry co-receptors, producing soluble antiviral factors, and killing the infected cells by the mechanisms similar to cytotoxic T lymphocytes (CTL) and NK cells. However, $\mathrm{V} \gamma 9 \mathrm{~V} \delta 2 \mathrm{~T}$ cells are found to be depleted in the advanced stages of the HIV infection and the insufficient number of $\mathrm{V} \gamma 9 \mathrm{~V} \delta 2$ $\mathrm{T}$ cells leads to increased potential for chronic inflammation. The envelope glycoprotein 120 (gp120) of CCR5 tropic strains of HIV could bind with the surface receptors CCR 5 and $\alpha 4 \beta 7$ expressing on $\gamma \delta$ T cells. This binding activates the P38 MAP kinase, which in turn promotes the Fas dependent caspase activation and induces the cell death (38). Further, when macaques were immunized with proteins like simian immunodeficiency virus (SIV) gp120 and gag p27 induced the production of chemokines CCL-3, CCL-4, CCL-5 (RANTES), which in turn bind with the CCR5 thus inhibiting the entry of HIV into the host (39). The levels of these chemokines were increased by the engagement of the ectopically expressed receptors called Natural Cytotoxic Receptors (NCRs) like NKP30 on the surface of the V $\delta 1 \mathrm{~T}$ cells that induced the production of high levels of significant chemokines and controlled the levels of HIV (40). However, activated V $\gamma 9 \mathrm{~V} \delta 2 \mathrm{~T}$ cells may directly suppress HIV replication by releasing CC-chemokines, competing with HIV for CCR5 entry coreceptor, and other soluble antiviral factors (41). Hence, the treatment approaches might include targeting proviral infection using the activation of $\mathrm{V} \gamma 9 \mathrm{~V} \delta 2 \mathrm{~T}$ cells with aminobisphosphonates and IL-2 to improve the anti-viral activity but not on the prolonged virus as the viral load is severe in this condition. $\gamma \delta \mathrm{T}$ cells coordinate activated innate immunity with adaptive antibody and $\mathrm{T}$ cell responses in preventive vaccination against $\mathrm{HIV}-1$ infection.

Apart from HIV, $\gamma \delta \mathrm{T}$ cells were known to be involved in following viral infections. $\gamma \delta \mathrm{T}$ cells are highly specific to the micro-environment in which they thrive and said to possess organ specific functions. $\gamma \delta \mathrm{T}$ cells in liver produce IL-17 is very essential for meliorating adenovirus mediated hepatitis, neutralizing IL-17 with antibodies aggravated these conditions (42). $\gamma \delta \mathrm{T}$ cells can compensate neutrophil IL-17 production. For instance, when mice were infected with Cryptococcus neoformans strain-H99 $\gamma$, which leads to neutropenia, IL-17 producing $\gamma \delta$ T cells mediated the regulation of innate and adaptive cells to mount a successful immune response (43). $\gamma \delta$ T cells were known to possess memory just like other adaptive immune cells. This character of $\gamma \delta \mathrm{T}$ cells was brought into limelight by the association of $\gamma \delta \mathrm{T}$ cells response on cytomegalovirus (44). $\gamma \delta \mathrm{T}$ cells were reduced in number during sepsis and acute reduction of these cells resulted in mortality of patients suffering with sepsis (45). The protective role of $\gamma \delta$ $\mathrm{T}$ cells have also been confirmed in few other infectious diseases caused by viruses including influenza virus, West Nile virus, herpes simplex virus, Epstein-Barr virus, and human hepatitis virus C.

\section{CANCER}

$\gamma \delta \mathrm{T}$ cells have a unique role in the immune-surveillance against malignancies and also an advantage over $\alpha \beta$ T cells because they can directly recognize molecules that are expressed on cancer cells without need of antigen processing and presentation (46). An important therapeutic feature of $\gamma \delta$ T cells is that these favorably kill cancer cells and show low reactivity toward non-transformed cells (47). Variable region of the V $\gamma 9 \mathrm{~V} \delta 2$ TCR plays a major role in recognition of the antigen (48). $\mathrm{V} \gamma 9 \mathrm{~V} \delta 2$ TCR recognize increased pool of endogenous IPP, which may only be found in tumor cells but not in healthy tissues. Activated V $\gamma 9 \mathrm{~V} \delta 2$ TCRs promote $\gamma \delta$ T cell cytotoxicity through increased secretion of perforin/granzymes, IFN- $\gamma$, and TNF- $\alpha$, IL-17, up-regulates expression of FasL and TNF-related apoptosis-inducing ligand (TRAIL) (49). Among the list of mediators promoting anti-cancer cytotoxicity mentioned above, IL-17 in tumor micro-environment remains controversial showing anti-tumor role and pro-tumor role. In several murine transplantable tumor models, anti-cancer drugs (such as oxaliplatin or anthracyclines) that induced immunogenic cell death, triggered the local invasion of IL-17 producing $\gamma \delta \mathrm{T}$ cells, which occurred before and was required for the subsequent invasion of tumor-reactive CTL $(50,51)$. However, it was shown that IL-17 producing $\gamma \delta$ cells acts as tumor promoting cells by inducing angiogenesis (52). In addition, Rei et al. demonstrated that IL-17 producing $\mathrm{V} \gamma 6^{+} \gamma \delta$ cells promotes tumor growth in the ID8 ovarian cancer model and thus opposes the widely accepted antitumor function of $\gamma \delta$ cells (53). In addition to TCR dependent pathways, NKG2D and DNAX accessory molecule-1 (DNAM-1) expressed on $\mathrm{V} \gamma 9 \mathrm{~V} \delta 2 \mathrm{~T}$ cells plays a critical role in anti-tumor 


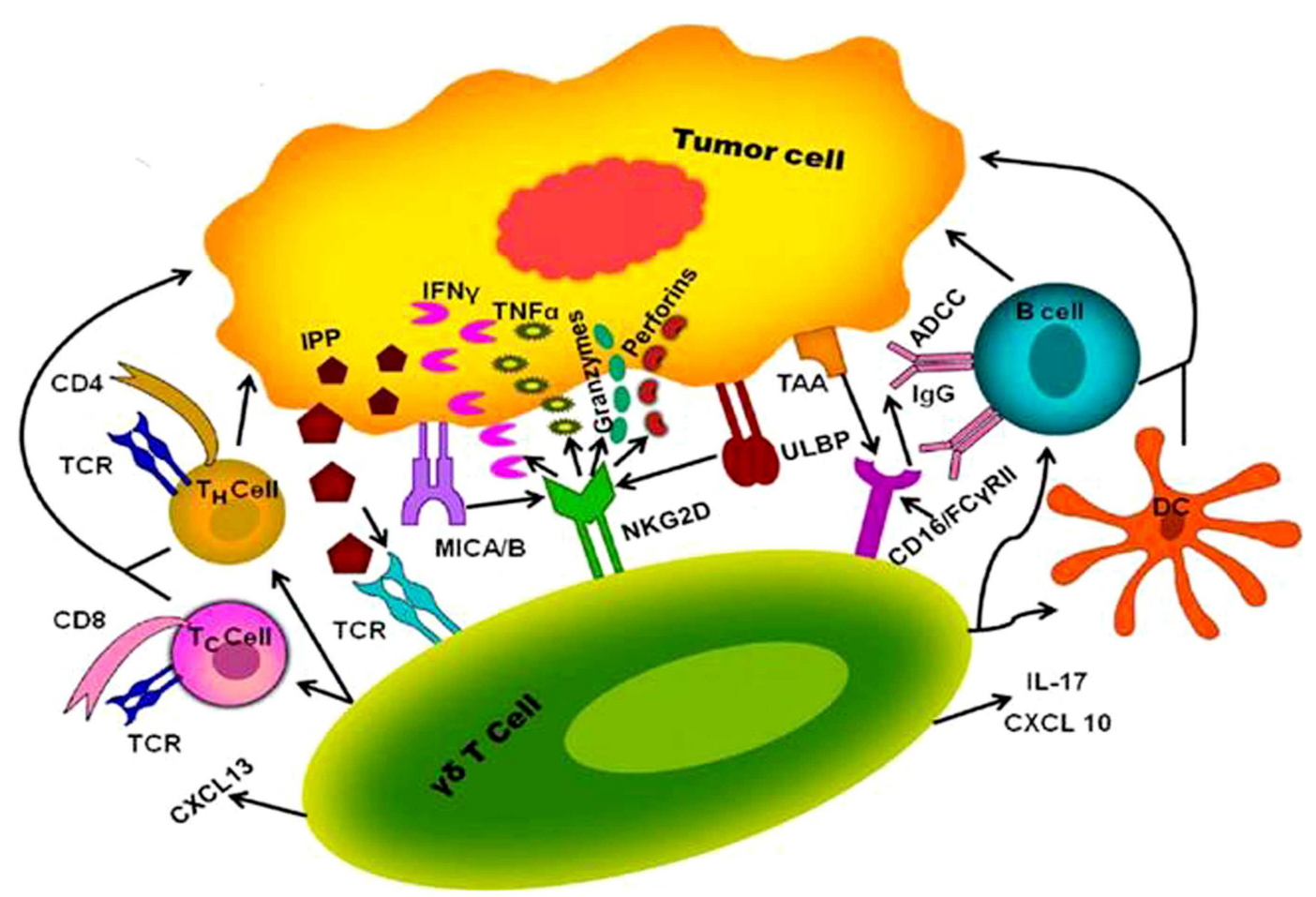

FIGURE 1 | Proposed mechanism of interaction between human $\gamma \delta$ T cell and tumor cell. $\gamma \delta$ T cells activated through interaction of $\gamma \delta$ T cell receptor with IPP produced via mevalonate pathway at higher concentration in tumor cell. Besides that NKG2D provides activation signals upon binding to MICA/B and ULBP of tumor antigens results in the release of cytokines and chemokines such as IFN- $\gamma$, TNF- $\alpha$, IL-2, IL-17, perforin, grazymes, CXCL-10, and $\mathrm{CXCL}-13$, which can directly lyse the tumor cell and can recruit other immune cells like $T$ cells ( $T_{H}$ cells and $T_{C}$ cells), B cells, and dendritic cells (DC) to aid killing of tumors. $\gamma \delta T$ cells expressing CD16 receptor ( $F C \gamma R I I)$ interacts with TAA mediate ADCC through activation of $B$ cell. response as shown in the Figure 1. NKG2D provides activation signals upon binding to non-classical MHC molecules of the MHC class-I chain-related molecules (MICA/B) and UL-16 binding protein (ULBP) families expressed on tumor cells (54). Nectin-like-5 expressed in carcinoma cells recognized by DNAX and provides activation signals (50). $\gamma \delta \mathrm{T}$ cells also express CD16 (FC $\gamma \mathrm{RIII})$ receptor, upon recognition of tumor associated antigens (TAA), CD16/FC $\gamma$ RIII receptor binds to Fc portion of immunoglobulin $\mathrm{G}$ (IgG) and leads to antibody-dependent cellular cytotoxicity (ADCC) (55). In addition to the cytokines, cytotoxic soluble factors, activated $\mathrm{V} \gamma 9 \mathrm{~V} \delta 2 \mathrm{~T}$ cells can produce large amount of chemokines like CXCL-13 and CXCL-10 result in the recruitment of B cells, macrophages, T cells, and NK cells toward the tumor micro-environment (49). It leads to inhibition of tumor growth and reduced survival of autologous tumor cells. $\gamma \delta \mathrm{T}$ cells have a unique capacity to present antigens to both CD8 and CD4 T cells and potentially elicit strong adaptive anti-tumor response.

Presently two strategies were applied for $\gamma \delta \mathrm{T}$ cell based cancer immunotherapy. One is the adoptive cell transfer of in vitro expanded V $\gamma 9 \mathrm{~V} \delta 2 \mathrm{~T}$ cells and second one is the administration of pAg or aminobisphosphonates along with low-dose recombinant IL-2 to stimulate $\mathrm{V} \gamma 9 \mathrm{~V} \delta 2 \mathrm{~T}$ cells in vivo. It has been shown that the two synthetic molecule drugs bromohydrin pyrophosphate (BrHPP) and zoledronate selectively activate human V $\gamma 9 \mathrm{~V} \delta 2 \mathrm{~T}$ cells in clinical trials. Bioactivity $\left(\mathrm{EC}_{50}\right)$ of $\operatorname{BrHPP}(56,57)$, and zoledronate (58) were $24 \mathrm{nM}$ and $1 \mu \mathrm{M}$, respectively to activate TCR V $\gamma 9 \mathrm{~V} \delta 2 \mathrm{~T}$ cell clones and PB mononuclear cells in vitro. Dieli et al. reported that increased survival rates in prostate cancer patients when administered zoledronate $(4 \mathrm{mg})$ in combination with IL-2 $\left(0.6 \times 10^{6} \mathrm{IU}\right)$ was observed (59). In another clinical trial (60), administration of low-dose IL-2 (0.25 to $\left.3 \times 10^{6} \mathrm{IU}\right)$ in combination with pamidronate $(90 \mathrm{mg})$ in multiple myeloma patients showed that five out of nine patients had significant in vivo activation and proliferation of $\mathrm{V} \gamma 9 \mathrm{~V} \delta 2 \mathrm{~T}$ cells, indicating that $\mathrm{V} \gamma 9 \mathrm{~V} \delta 2 \mathrm{~T}$ cells might contribute to this anti lymphoma effect. V $\gamma 9 \mathrm{~V} \delta 2 \mathrm{~T}$ cells from tumor infiltrate lymphocytes (TIL) of colorectal cancer are able to eliminate cancer cells in vivo and have been associated with reduced metastasis and longer mean survival (61). BrHPP activated TCR $\mathrm{V} \gamma 9^{+} \gamma \delta \mathrm{T}$ cells obtained from healthy subjects co-incubated in vitro with B-lymphoma cell targets coated with rituximab, enhance ADCC of target cells (62). In primates, administration of pAg synthetic analogs and low doses of IL-2 expand $\mathrm{V} \gamma 9 \mathrm{~V} \delta 2 \mathrm{~T}$ cells in lung tissue, which in turn confer activity against human non-small cell lung cancer (NSCLC) cell lines by increasing the secretion of IFN- $\gamma$, TNF$\alpha$, and TRAIL (63). Phospho Ag-expanded V $\delta 2$ T cells infusion has also been tested in lymphoid neoplasms and renal cancer. In metastatic renal carcinoma, six cycles of adaptive immunotherapy with infusions of phospho Ag-expanded $\gamma \delta \mathrm{T}$ cells plus zoledronic acid $(4 \mathrm{mg})$ and low doses of IL-2 $\left(1.4 \times 10^{6} \mathrm{IU}\right)$ caused complete 
remission without progression for 2 years (64). In vitro studies reported $\gamma \delta \mathrm{T}$ cells killing efficacy was increased against three cervical cancer cells pretreated with pamidronate and proved by LDH cytotoxicity test (65). Elevated levels of $\mathrm{V} \gamma 9 \mathrm{~V} \delta 2 \mathrm{~T}$ cells in the liver were found in hepatocellular carcinoma (HCC) patients as well as tumor bearing mice compared to healthy controls, indicating the importance of $\mathrm{V} \gamma 9 \mathrm{~V} \delta 2 \mathrm{~T}$ cell in the anti-tumor immunity (66). Oberg et al. reported increased $\gamma \delta \mathrm{T}$ cell cytotoxicity against pancreatic ductal adenocarcinomas (PDAC) in vitro and in vivo in immunocompromised mice, when administered healthy donors $\gamma \delta \mathrm{T}$ cell with Her2/V $\gamma 9$ bispecific antibodies (67). Hence, novel regimens combining $\gamma \delta \mathrm{T}$ cells with drugs or monoclonal antibodies would be helpful for treatment of solid tumors and hematological malignancies.

\section{BURNS AND WOUNDS}

$\gamma \delta \mathrm{T}$ cells participate in several aspects of healing from burn injuries and wounds. Healing is a dynamic and complex process requiring constant communication between cells in the form of cytokine release, cell-to-cell contacts, and cell-to-matrix interactions. The epidermis is a barrier tissue that is exposed to the environment and susceptible to injury. $\gamma \delta \mathrm{T}$ cells are found in both epidermis and dermis of human skin express $\mathrm{V} \delta 1$ chain. These skin-resident $T$ cells involved in reepithelization of acute and chronic wounds. Human epidermal $\alpha \beta$ and $V \delta 1$ bearing $\mathrm{T}$ cells are able to produce insulin like growth factor upon activation and promote wound healing in a skin organ culture model (68). Murine epidermal $\gamma \delta$ T cells are named as DETCs because of their unique dendritic morphology. DETC express an invariant $\mathrm{V} \gamma 3 \mathrm{~V} \delta 1^{+}$TCR. Oppeltz et al. reported that epidermal $\gamma \delta \mathrm{T}$ cells play a major role in the expression of inducible nitric oxide synthase (iNOS) at the burn wound site and is important in wound closure and collagen deposition (69). Recently, it has been suggested that DETC participate in tissue repair, likely through the production of Th2 and Th17 cytokines (70), chemokines, and growth factors. Hence the immediate goal of DETC is to repair wound and maintain tissue integrity and homeostasis.

Wound occurs as a result of trauma, infection or by the pathological infections. Cellular damage and stressed keratinocytes produce an unknown antigen, which binds with the TCR of DETC, which are proximal to the wound (71). Further, DETC changes its morphology and become rounded with in $4 \mathrm{~h}$ post wounding (72). The rounded morphology of DETC correlates with functional activity. The distal DETC to the wound retain dendritic and maintain tissue homeostasis. Activated DETC produce TNF- $\alpha$, insulin growth factor (IGF)-1, KGF-1, KGF-2, and up regulate the activation markers CD25 and CD69 in response to the epithelial damage (73). Rapamycin, an immunosuppressor that is known to regulate the DETC rounding by targeting the serine threonine kinase, cause delay in cytokine production and wound healing (74). DETCs are shown to produce lymphoid associated thymosin- $\beta 4$ variant in contact dermatitis that exhibits the anti-inflammatory role (75). In normal condition, DETCs are slightly activated at the epidermal region by expressing the activation markers CD25, CD69, and also secrete some cytokines in low amount that allows them for quick activation in response to local trauma (76). DETC express the co-stimulatory activating receptors like NKG2D, and H60c, ligand expressed on wounded epidermis and shown to provide costimulatory signals with NKG2D participating in TCR mediated signaling (77). A prominent signaling by co-stimulatory mode of DETC activation is by junctional adhesion molecule-like protein (JAML) that is expressed by the DETC. The recognition of JAML to its ligand coxsackie and adenovirus receptor (CAR) expressed by the keratinocytes results in the recruitment of phosphoinositide 3-kinase (PI3K) (78) and also with the HLA4E10 (79) stimulatory antibody that helps in promoting wound healing as shown in Figure 2. Recently, it was found that plexin B2 expressed on keratinocytes and CD100 an intra cellular signaling domain of DETCs shows much interaction and makes the cellular rounding via signals through ERK kinase and cofilin (80). Rani et al. reported that, $\gamma \delta \mathrm{T}$ cells regulate myeloid cell activity, which in turn enhances macrophage influx into the wound site to repair wound (81).

$\gamma \delta \mathrm{T}$ cells also participate in the repair of epithelia in other organs, such as intestine, lung, and cornea. $\gamma \delta \mathrm{T}$ cells play a key role in the maintaining of intestinal mucosa by producing KGF. Mice lacking $\gamma \delta$ T cells treated with a dextran sodium sulfate (DSS), exhibit severe mucosal injury and decreased epithelial cell proliferation (82). Mice deficient for TCR $\delta$ chain $\left(\mathrm{TCR} \delta^{-/-}\right)$exhibit significantly reduced inflammation and epithelial repair in the lung after bleomycin treatment (83) and also in the corneal epithelial abrasion (84). In the lung injury, $\gamma \delta \mathrm{T}$ cells are required for the neutrophils influx and also produce IL-17, which are responsible for the inflammatory response and epithelial repair (85). Corneal healing involves both epithelium and sensory nerves that have a trophic effect for the epithelium. Intracellular cell adhesion molecule (ICAM)-1 and CCL20 chemokine are necessary for attracting the $\gamma \delta$ T cells into the healing epithelium (86). $\gamma \delta$ T cells are responsible for the secretion of cytokines such as IL-17, IL-22, and the influx of neutrophils and platelets, which contribute to the epithelium healing. Accumulation of neutrophils and platelets leads to the rise in vascular endothelial growth factor (VEGF), which is required for nerve regeneration (87).

\section{AUTOIMMUNE DISEASES}

Autoimmune diseases are characterized by abnormal immune responses to self antigens. These diseases are induced by many environmental factors on a genetically susceptible background, which lead to production of huge number of inflammatory cytokines and auto-antibodies to make path for the outbreak and progression of the disease. The roles of $\gamma \delta$ T cells in autoimmune diseases are not yet very clear. Bendersky et al. showed that elevated number of $\mathrm{V} \gamma 9 \mathrm{~V} \delta 2 \mathrm{~T}$ cells $(\sim 35 \%)$ in synovial fluid and $\mathrm{PB}$, produced TNF- $\alpha$ and IFN- $\gamma$ during the pathogenesis of juvenile idiopathic arthritis (JIA). Further, activation of $\gamma \delta \mathrm{T}$ cells leads to apoptosis of synovial fibroblasts, the effect of which is manifested in JIA (88). $\gamma \delta$ T cells in intestine were significantly reduced during intestinal inflammation, which leads to the uncontrolled activity of $\mathrm{CD}^{+} \mathrm{T}$ helper cells to cause autoimmune inflammatory bowel disease called Crohn's disease (89). The role of $\gamma \delta \mathrm{T}$ cells in allergic encephalomyelitis and multiple sclerosis is ambiguous. $\gamma \delta \mathrm{T}$ cells were certainly abundant in cerebrospinal fluid of the respective mouse models but their precise role is not yet established (90). In non-obese diabetic mouse model, $\gamma \delta \mathrm{T}$ 


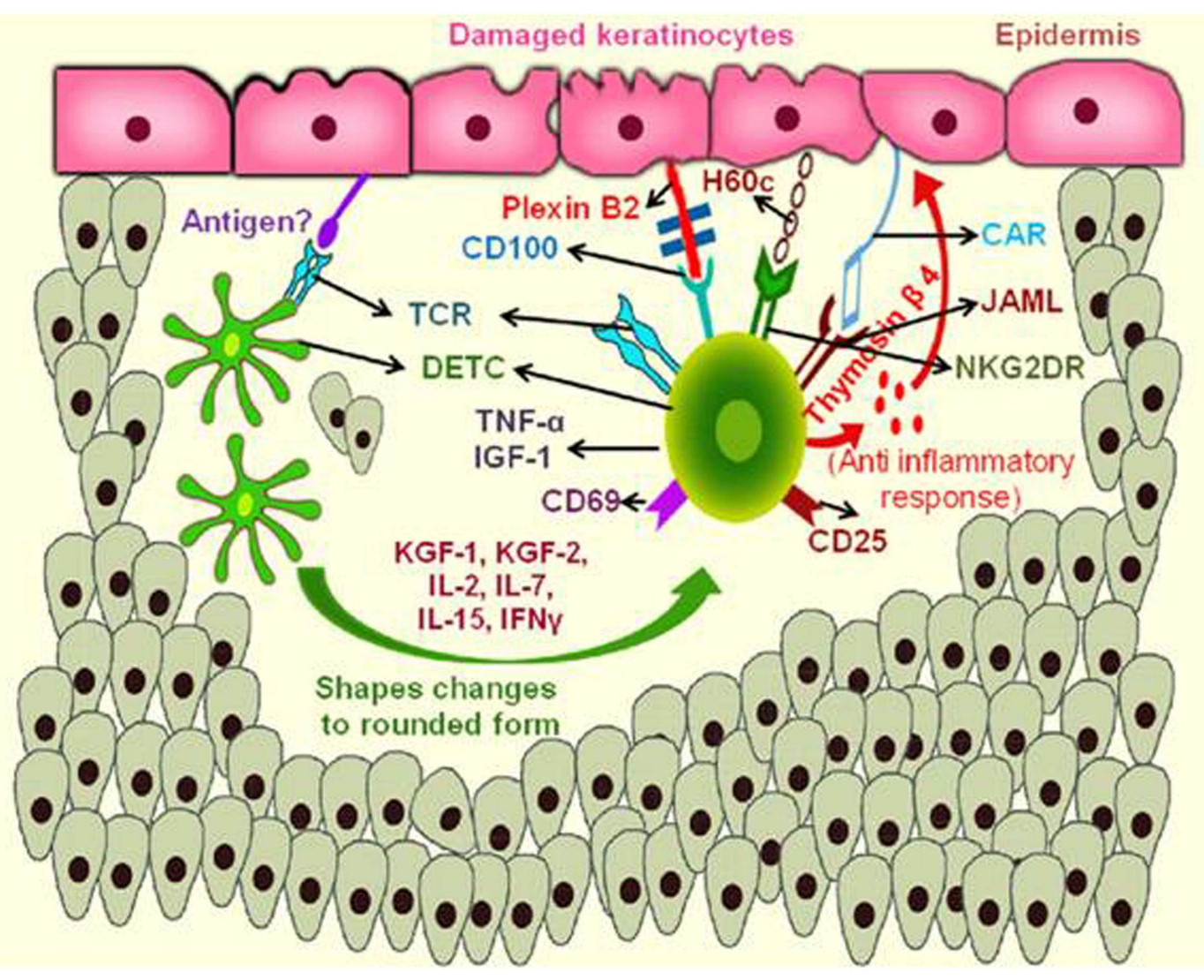

FIGURE 2 | Mechanism of action of murine skin resident $\gamma \delta$ T cells in wound repair. During keratinocyte damage, the epidermal $\gamma \delta \mathrm{T}$ cells (DETCs) are activated upon recognition of an unknown antigen, rounding of the DETCs occur and produce thymosin $\beta 4$ and cytokines like TNF- $\alpha$, IFN- $\gamma$, and IL-2 required for anti-inflammatory response and wound healing.
Engagement of NKG2DR with $\mathrm{H} 60 \mathrm{c}$ and JAML-CAR interactions also enhances the production of these cytokines and provide epidermal repair. (JAML, junction adhesion molecule like protein; CAR, coxsackie and adenovirus receptor; TNF, tumor necrosis factor; IFN, interferon; IL, interleukin; NKG2DR, natural killer cell activating receptor). cells infiltrate into islet cells and secrete IL-17 to cause apoptosis. Antibody mediated blockade of IL-17 stopped the process and rescued mouse from diabetes (91). $\gamma \delta$ T cells cross react with aminoacyl-tRNA synthetases of the muscle cells that lead to the pathogenesis of myositis, an inflammation of muscle tissues caused by autoimmune T cells (92).

Behcet's disease is an immune mediated disorder that is often associated with the symptoms like ulceration of mucous membrane, skin, and ocular problems. In general, normal individuals consist of $\mathrm{CD}_{45 \mathrm{RA}^{-}} \mathrm{CD}^{-} 5 \mathrm{RO}^{+} \mathrm{V} \gamma 9^{+} \mathrm{V} \delta 2^{+} \mathrm{T}$ cells but as the

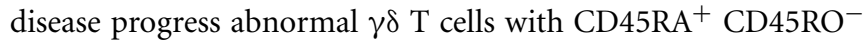
$\mathrm{V} \gamma 9^{+} \mathrm{V} \delta 2^{+}$phenotype are increased in number and activated, then produced IL-2R in patients suffering with Behcet's disease (88). Infliximab, is a chimeric monoclonal antibody against TNF- $\alpha$, suppress the $\mathrm{V} \gamma 9 \mathrm{~V} \delta 2 \mathrm{~T}$ cell expansion and activation by blocking the TNF receptor on $\mathrm{V} \gamma 9 \mathrm{~V} \delta 2 \mathrm{~T}$ cells. Moreover, it also reduces the cell-mediated immune responses by reducing the expression TNF RII, perforin, granzyme-A, and IFN- $\gamma$ production from $\mathrm{V} \gamma 9 \mathrm{~V} \delta 2$ T cell (93).

Psoriasis is speculated as the T cell operated chronic inflammatory skin disease (94), but the mechanisms of pathogenesis are still poorly understood. Chemokine receptor CCR6 (receptor for a CCL20) is very abundant in psoriatic skin $\mathrm{T}$ cells. Chemokine receptors are transmembrane proteins that are activated by chemokines, which play key roles in cell trafficking, cell motility, and survival. CCR6 regulates epidermal trafficking of $\gamma \delta$ T cell subsets in the skin (95). The chemokine receptor CCR6 is expressed on the Th17 cells and $\gamma \delta$ T cells, which produce cytokines like IL-17 and IL-22, TNF- $\alpha$, and IL-20 (94). IL-22 plays a key role in the activation of immunity and has been implicated in the pathogenesis of psoriasis (96). $\gamma \delta \mathrm{T}$ cells from CCR6 KO mice not only failed to accumulate in the epidermis after IL-23 treatment and even though entered into the epidermis produced low amounts of IL-22 compared with wild type $\gamma \delta$ T cells. Hence, this data suggest that not only recruitment but also function of $\gamma \delta \mathrm{T}$ cells may be impaired in the absence of CCR6 (97). Laggner et al. showed that, redistribution of $\mathrm{V} \gamma 9 \mathrm{~V} \delta 2 \mathrm{~T}$ cells from $\mathrm{PB}$ to skin in psoriasis patients as compared to the healthy control. These skin homing $\mathrm{V} \gamma 9 \mathrm{~V} \delta 2 \mathrm{~T}$ cells produce the psoriasis relevant cytokines IFN- $\gamma$, TNF- $\alpha$, and IL-17A similar to blood derived V $\gamma 9 \mathrm{~V} \delta 2 \mathrm{~T}$ cells $(98,99)$. Prominent roles for skin homing V $\gamma 9 \mathrm{~V} \delta 2 \mathrm{~T}$ cells are influencing the resident immune and epithelial cells by the 
Table 1 |Antigen recognition and functions of $\gamma \delta$ T cells in various diseases. $\gamma \delta$ T cells recognizes various antigenic factors and produce respective chemokines and cytokines to protect immune system against from different diseases like pathogenic infections, cancer, wound repair, and autoimmune.

S. No. Disease Stimulator/activator for $\gamma \delta \mathrm{T}$ cells $\quad$ Function of $\gamma \delta \mathrm{T}$ cells in immune-protection

1. Pathogenic infections

a. Tuberculosis

(M. tuberculosis)

b. Malaria

(P. falciparum)

c. AIDS (HIV)

2. Cancer

3. Wound repair

HMBPP produced by the 2-C-methyl-D-erythritol

4-phosphate (MEP) pathway in microorganisms

Schizont associated antigen (SAA) and HMBPP

Recognize the envelope protein GP 120 by CCR5 receptor on $\mathrm{V} \gamma 9 \mathrm{~V} \delta 2 \mathrm{~T}$ cells

$\mathrm{V} \gamma 9 \mathrm{~V} \delta 2 \mathrm{TCR}$ recognizes endogenous IPP, produced

by mevalonate pathway in tumor cells

NKG2D expressed on $\gamma \delta$ T cells recognizes MICA/B and ULBP families expressed on tumor cells

Non-specific antigen recognition by DETC

4.

Autoimmune diseases

Recognizes self antigens by $\gamma \delta T C R$
Produce IL-22, IL-17, and IFN- $\gamma$. Regulating both innate and adaptive immunity

IL-10, IL2, IL-1 $\beta$, and IFN- $\gamma$ degranulation of infected RBC and merozoites

Activates P38 MAP kinase, which promotes the FAS dependent caspase activation and induces the cell death Increased secretion of perforin/granzymes, TNF- $\alpha$, IFN- $\gamma$, and suppress the tumor

Produce IFN- $\gamma$, IL-17, and chemokines, which recruit the macrophages, NK cells, B cells, and T cells

IL-2, TNF- $\alpha$, IFN- $\gamma$, KGF-1, and KGF-2 are produced against the damaged keratinocytes result in the healing of wound

Enhances the production of IL-17, IL-23, and IFN- $\gamma$. The exact mechanism of $\gamma \delta T$ cells in these diseases is not yet clear

HMBPP, (E)-4-hydroxy-3-methyl-but-2-enyl pyrophosphate; $\gamma \delta$ TCR, $\gamma \delta$ T cell receptor; IFN, interferon; IL, interleukin; GP 120, glycoprotein; CCR, chemokine receptor; MAP, mitogen activated protein; NKG2D, natural killer cell activating receptor; MICA/B, MHC class-l chain-related molecule; ULBP, UL-16 binding protein; TNF, tumor necrosis factor; DETC, dendritic epidermal $\gamma \delta T$ cell; KGF, keratinocyte growth factor.

rapid release of pro-inflammatory cytokines, the recruitment of immune cells from the circulation, and in tissue remodeling by the release of growth factors (99), which make $\mathrm{V} \gamma 9 \mathrm{~V} \delta 2 \mathrm{~T}$ cells as the biomarker of psoriasis.

$\gamma \delta \mathrm{T}$ cells show enhanced antigen-presenting cell (APC) functions, which may play a role in the pathogenesis of RA by over activating $\mathrm{T}$ and $\mathrm{B}$ cells. Abnormal activation of Th1 and Th17 cells result in the production of pro-inflammatory cytokines, which play crucial role in the pathogenesis of RA (100). Peripheral $\mathrm{V} \gamma 9 \mathrm{~V} \delta 2 \mathrm{~T}$ cells after stimulation with IPP in vitro are shown to upregulate the expression of APC specific molecules HLA-DR and CD80/86 and presented soluble antigens and synthetic peptides to $\mathrm{CD} 4^{+} \mathrm{T}$ cells and $\mathrm{B}$ cells thus contributing to activation of $\mathrm{CD} 4^{+}$ $\mathrm{T}$ cells and being associated with RA onset and disease progression (100). A subset of $\mathrm{CD} 27^{+} \mathrm{CD} 25^{\text {high }} \mathrm{V} \delta 1 \mathrm{~T}$ cells expressing FoxP3 were gradually decreased in the PB of systemic lupus erythematosus patients progressing in the pathogenesis of SLE and these regulatory $\gamma \delta$ T cells could be generated in vitro when stimulated with anti $\gamma \delta$-TCR in presence of IL-2 and transforming growth factor-beta (TGF- $\beta$ ) (101). The activating marker CD69 and HLA-DR were up regulated while the expression levels of the inhibiting receptor CD94/NKG2A remained low after the antigen stimulation on these $\gamma \delta \mathrm{T}$ cells, upon activation might lead to the over activation of $\gamma \delta$ T cells in patients with SLE (102).

Graft rejection is a serious problem during transplanting of solid organs. Conventionally, the B cells and $\alpha \beta$ T cells of adaptive immune system were considered to be the key in this phenomenon as they have immune memory and can bind numerous antigens. However, there is an evidence that $\gamma \delta \mathrm{T}$ cells play a vital role in graft rejection. Gorczynski et al. studied the role of $\gamma \delta \mathrm{T}$ cells in skin graft rejection using mouse model (103). $\gamma \delta$ T cells were not restricted by immunosuppressive drugs during organ transplantation. Some subsets of $\gamma \delta \mathrm{T}$ cells expand oligo clonally and the reasons for this expansion are unknown but may be linked to persistent viral infections. It has been suggested that quantification of $\gamma \delta \mathrm{T}$ cells in PB may not be essential to decide graft tolerance (104). The known role of $\gamma \delta \mathrm{T}$ cells in autoimmune diseases is limited, so an extensive research has to be focused particularly on the effects of these cells in the pathogenesis and development of disease and ultimately for the development of $\gamma \delta \mathrm{T}$ cell based therapies.

$\gamma \delta \mathrm{T}$ cells functions in various diseases, described in the review are summarized in the Table $\mathbf{1 .}$

\section{IMMUNOTHERAPY}

Immunotherapy has become an increasingly attractive option for the treatment of cancer (105). $\gamma \delta \mathrm{T}$ cells may be an excellent target for modulation of immune responses in human diseases. Enhancing $\gamma \delta \mathrm{T}$ cell functions may open the possibility to formulate new immunotherapeutic regimens, which could impact the improvement of immune control of various diseases. Aminobisphosphonates like zoledronate, pamidronate, and BrHPP were well-studied among the numerous activators of $\mathrm{V} \gamma 9 \mathrm{~V} \delta 2 \mathrm{~T}$ cells. IPP is an intermediate metabolite of mevalonate pathway. Bisphosphonates may activate $\mathrm{V} \gamma 9 \mathrm{~V} \delta 2 \mathrm{~T}$ cells, by inhibiting the key enzyme farnesyl pyrophosphate synthase of mevalonate pathway in certain tumors leads to upregulating the endogenous pool of IPP. Mevalonate is the product of HMG-CoA reductase, a rate limiting enzyme subject to tight regulation. However, high exogenous mevalonate concentration would bypass normal regulation and indirectly 
stimulates $\mathrm{V} \gamma 9 \mathrm{~V} \delta 2 \mathrm{~T}$ cells by increasing endogenous IPP levels (106). Taken together, bisphosphonates and mevalonate may activate V $\gamma 9 \mathrm{~V} \delta 2 \mathrm{~T}$ cells and aid in curing bacterial infections (107). Bisphosphonates were proven to treat gliomas (108). A clinical trial of immunotherapy using a combination of zoledronate, a bisphosphonate, and IL-2 was found to alleviate renal cell carcinoma (109). HMBPP is one of the key ligands that activate $\mathrm{V} \gamma 9 \mathrm{~V} \delta 2 \mathrm{~T}$ cells. HMBPP is produced by the 2-C-methyl-D-erythritol 4-phosphate (MEP) biosynthetic pathway in microorganisms. HMBPP is nearly 1000 -fold more effective than IPP for the in vitro activation of V $\gamma 9 \mathrm{~V} \delta 2 \mathrm{~T}$ cells. V $\gamma 9 \mathrm{~V} \delta 2 \mathrm{~T}$ cells express surface marker CCR5, which is recognized by gp120 of HIV. This leads to apoptosis of HIV infected cells through a caspase mediated pathway. It has been suggested that by triggering rapid proliferation of $\mathrm{V} \gamma 9 \mathrm{~V} \delta 2$ $\mathrm{T}$ cells may help in curing HIV infection (110). $\gamma \delta \mathrm{T}$ cell based immunotherapy might have a beneficial effect in patients with chronic hepatitis $\mathrm{C}$ virus infection (111).

$\alpha \beta$ T cell populations potently attack specific targets but are limited by their specificity, where as $\gamma \delta \mathrm{T}$ cells in combination with tumor-targeting antibodies might provide anti-tumor cytotoxic effects and also long-lasting protection upon antigen presentation. $\gamma \delta$ T cells have dual role of stimulating both $\gamma \delta$ T cell-directed anti-tumor activity and antigen-specific CD 4 and CD8 $\alpha \beta$ T cell responses. $\gamma \delta$ T cells are attractive agents for cancer immunotherapy because they are not MHC restricted like conventional $\mathrm{T}$ cells. So, a single vaccine can be used in all individuals regardless of MHC haplotype (112). Memory like expansion of V $\gamma 9 \mathrm{~V} \delta 2$ $\mathrm{T}$ cells has been reported in primates after subclinical systemic infection and reinfection with attenuated Listeria monocytogenes strains (20). $\gamma \delta$ T cells acquire memory in order to play protective antiviral and anti-tumor roles. The direct or indirect stimulation of $\gamma \delta$ T cells by TLR agonists could be a strategy to optimize Th1 mediated immune responses as adjuvant in clinical trial of cancer immunotherapy (113). Recent studies suggest that, combination of $\gamma \delta \mathrm{T}$ cells with therapeutic monoclonal antibodies can efficiently mediate ADCC against tumors (114). Chronic wounds are an increasing clinical problem, understanding advanced mechanisms of DETC during wounds and burns in humans suggesting possible therapeutic targets for tissue repair and skin homeostasis. Disabling $\gamma \delta \mathrm{T}$ cells at the specific site by using monoclonal antibodies is a viable therapeutic option for the treatment of autoimmune diseases. Peters et al. reported immunosuppression of $\gamma \delta \mathrm{T}$ cells by using anti-CD28 mAb and antagonized by TLR- 2 ligands (113). Suppressive $\gamma \delta$ T cells could have major therapeutic potential for the control of autoimmunity or allergic reactions. Enhancing the activity of Tregs, which inturn secrete PD-1 and CTLA-4 to suppress the activity of $\gamma \delta$ T cells, could improve treatment for the autoimmune diseases (115). Modulation of these immunosuppressive check points may be interesting clinical trial in the $\gamma \delta$ T cells based immunotherapy.

\section{CONCLUDING REMARIS AND FUTURE DIRECTIONS}

The role of $\gamma \delta \mathrm{T}$ cells in immunotherapy has gained specific importance due to their prominent function involving directly or indirectly in the rehabilitation of the diseases. $\gamma \delta \mathrm{T}$ cells act as connecting bridge between both the innate and adaptive immune responses without the antigen presentation and producing some important key cytokines like IFN- $\gamma$ and TNF- $\alpha$. When stimulated with the combination of aminobisphosphonates and IL-2 activate the $\mathrm{V} \gamma 9 \mathrm{~V} \delta 2 \mathrm{~T}$ cells further and they can also act as the APCs to treat particular infections and tumors. Factors that potentiate the pathogenesis of $\gamma \delta$ T cells in autoimmune diseases are yet to be revealed so as to develop drugs, which can target the $\gamma \delta$ $\mathrm{T}$ cell in particular. New strategies and models that target the molecules involved during disease onset and progression need to be developed, as this makes a pavement for $\gamma \delta \mathrm{T}$ cell based immunotherapy. New ligands and chemokines responsible for activation and effector functions of $\gamma \delta \mathrm{T}$ cells are to be deciphered. Many new molecules and proteins can be designed to trigger the $\gamma \delta \mathrm{T}$ cell through a TCR independent pathway. Vaccines have to be developed to enhance the production levels of chemokines and cytokines by these $\gamma \delta$ T cells at the tumor site. For the preparation of large number of cells for adoptive cell transfer, it is necessary to develop better antigens, which stimulate $\gamma \delta \mathrm{T}$ cell expansion in vitro. Further, clinical trials are required for the $\gamma \delta$ T cell targeted immunotherapy in case of chronic infections and diseases. Further research might shed more light on the in depth understanding of the underlying mechanisms of the antigen recognition and key factors influencing the $\gamma \delta$ T cell production during the disease.

\section{ACKNOWLEDGMENTS}

This work was supported by grants from Science and Engineering Research Board (SERB), India (Grant \#: SR/FT/LS-149/2010) and Council of scientific and industrial research (CSIR), India, (Grant\# 37(1517)/11/EMR-II) to Dakshayani Lomada. The authors would like to acknowledge Mr. D. Sravan Kumar Gowd and Mr. N. Siva Shanker, for their assistance.

\section{REFERENCES}

1. Holtmeier W, Kabelitz D. Gammadelta T cells link innate and adaptive immune responses. Chem Immunol Allergy (2005) 86:151-83. doi:10.1159/000086659

2. Hayday AC. [gamma][delta] cells: a right time and a right place for a conserved third way of protection. Annu Rev Immunol (2000) 18:975-1026. doi:10.1146/annurev.immunol.18.1.975

3. Prinz I, Silva-Santos B, Pennington DJ. Functional development of gammadelta T cells. Eur J Immunol (2013) 43(8):1988-94. doi:10.1002/eji.201343759

4. Havran WL, Allison JP. Origin of Thy-1+ dendritic epidermal cells of adult mice from fetal thymic precursors. Nature (1990) 344(6261):68-70. doi:10. 1038/344068a0

5. Kabelitz D, Peters C, Wesch D, Oberg HH. Regulatory functions of gammadelta T cells. Int Immunopharmacol (2013) 16(3):382-7. doi:10.1016/j.intimp.2013. 01.022

6. Ramsburg E, Tigelaar R, Craft J, Hayday A. Age-dependent requirement for gammadelta $\mathrm{T}$ cells in the primary but not secondary protective immune response against an intestinal parasite. J Exp Med (2003) 198(9):1403-14. doi:10.1084/jem.20030050

7. Vermijlen D, Brouwer M, Donner C, Liesnard C, Tackoen M, Van Rysselberge $\mathrm{M}$, et al. Human cytomegalovirus elicits fetal gammadelta $\mathrm{T}$ cell responses in utero. J Exp Med (2010) 207(4):807-21. doi:10.1084/jem.20090348

8. Born WK, Kemal Aydintug M, O’Brien RL. Diversity of gammadelta T-cell antigens. Cell Mol Immunol (2013) 10(1):13-20. doi:10.1038/cmi.2012.45

9. Di Carlo E, Bocca P, Emionite L, Cilli M, Cipollone G, Morandi F, et al. Mechanisms of the antitumor activity of human Vgamma9Vdelta2 T cells in combination with zoledronic acid in a preclinical model of neuroblastoma. Mol Ther (2013) 21(5):1034-43. doi:10.1038/mt.2013.38

10. Vavassori S, Kumar A, Wan GS, Ramanjaneyulu GS, Cavallari M, El Daker S, et al. Butyrophilin 3A1 binds phosphorylated antigens and stimulates human gammadelta T cells. Nat Immunol (2013) 14(9):908-16. doi:10.1038/ni.2665 
11. Sandstrom A, Peigne CM, Leger A, Crooks JE, Konczak F, Gesnel MC, et al. The intracellular B30.2 domain of butyrophilin 3A1 binds phosphoantigens to mediate activation of human Vgamma9Vdelta2 T cells. Immunity (2014) 40(4):490-500. doi:10.1016/j.immuni.2014.03.003

12. Uldrich AP, Le Nours J, Pellicci DG, Gherardin NA, McPherson KG, Lim RT, et al. CD1d-lipid antigen recognition by the gammadelta TCR. Nat Immunol (2013) 14(11):1137-45. doi:10.1038/ni.2713

13. Gogoi D, Dar AA, Chiplunkar SV. Involvement of Notch in activation and effector functions of gammadelta T cells. J Immunol (2014) 192(5):2054-62. doi:10.4049/jimmunol.1300369

14. Sabbione F, Gabelloni ML, Ernst G, Gori MS, Salamone G, Oleastro M, et al. Neutrophils suppress gammadelta T-cell function. Eur J Immunol (2014) 44(3):819-30. doi:10.1002/eji.201343664

15. Peters C, Oberg HH, Kabelitz D, Wesch D. Phenotype and regulation of immunosuppressive Vdelta2-expressing gammadelta T cells. Cell Mol Life Sci (2014) 71(10):1943-60. doi:10.1007/s00018-013-1467-1

16. Chien YH, Meyer C, Bonneville M. Gammadelta T cells: first line of defense and beyond. Annu Rev Immunol (2014) 32:121-55. doi:10.1146/annurevimmunol-032713-120216

17. Su D, Shen M, Li X, Sun L. Roles of gammadelta T cells in the pathogenesis of autoimmune diseases. Clin Dev Immunol (2013) 2013:985753. doi:10.1155/2013/985753

18. Pantelyushin S, Haak S, Ingold B, Kulig P, Heppner FL, Navarini AA, et al. Rorgammat+ innate lymphocytes and gammadelta $\mathrm{T}$ cells initiate psoriasiform plaque formation in mice. J Clin Invest (2012) 122(6):2252-6. doi:10. $1172 /$ jci61862

19. Eurosurveillance Editorial Team. WHO publishes global tuberculosis report 2013. Euro Surveill (2013) 18(43):20615. Available from: http://www. eurosurveillance.org/ViewArticle.aspx?ArticleId=20615

20. Chen ZW. Diverse immunological roles of gammadelta T cells. Cell Mol Immunol (2013) 10(1):1. doi:10.1038/cmi.2012.73

21. Eberl M, Hintz M, Reichenberg A, Kollas AK, Wiesner J, Jomaa H. Microbial isoprenoid biosynthesis and human gammadelta $\mathrm{T}$ cell activation. FEBS Lett (2003) 544(1-3):4-10. doi:10.1016/S0014-5793(03)00483-6

22. Price SJ, Hope JC. Enhanced secretion of interferon-gamma by bovine gammadelta T cells induced by coculture with Mycobacterium bovis-infected dendritic cells: evidence for reciprocal activating signals. Immunology (2009) 126(2):201-8. doi:10.1111/j.1365-2567.2008.02889.x

23. Chen ZW. Multifunctional immune responses of HMBPP-specific Vgamma2Vdelta2 T cells in M. tuberculosis and other infections. Cell Mol Immunol (2013) 10(1):58-64. Epub 2012/11/14. doi:10.1038/cmi.2012.46

24. Chen CY, Huang D, Yao S, Halliday L, Zeng G, Wang RC, et al. IL-2 simultaneously expands Foxp3+ T regulatory and T effector cells and confers resistance to severe tuberculosis (TB): implicative Treg-T effector cooperation in immunity to TB. J Immunol (2012) 188(9):4278-88. doi:10.4049/jimmunol.1101291

25. Yao S, Huang D, Chen CY, Halliday L, Zeng G, Wang RC, et al. Differentiation, distribution and gammadelta $\mathrm{T}$ cell-driven regulation of IL-22-producing $\mathrm{T}$ cells in tuberculosis. PLoS Pathog (2010) 6(2):e1000789. doi:10.1371/journal. ppat. 1000789

26. Peng MY, Wang ZH, Yao CY, Jiang LN, Jin QL, Wang J, et al. Interleukin 17producing gamma delta $\mathrm{T}$ cells increased in patients with active pulmonary tuberculosis. Cell Mol Immunol (2008) 5(3):203-8. doi:10.1038/cmi.2008.25

27. Zheng J, Liu Y, Lau YL, Tu W. Gammadelta-T cells: an unpolished sword in human anti-infection immunity. Cell Mol Immunol (2013) 10(1):50-7. doi: $10.1038 / \mathrm{cmi} .2012 .43$

28. WHO advisory committee on immunization and vaccine related implementation research (IVIR, formerly QUIVER): executive summary report of 7th meeting. Wkly Epidemiol Rec (2013) 88(44/45):486-8.

29. Battistini L, Caccamo N, Borsellino G, Meraviglia S, Angelini DF, Dieli $\mathrm{F}$, et al. Homing and memory patterns of human gammadelta $\mathrm{T}$ cells in physiopathological situations. Microbes Infect (2005) 7(3):510-7. doi:10.1016/ j.micinf.2004.12.008

30. Inoue S, Niikura M, Takeo S, Mineo S, Kawakami Y, Uchida A, et al. Enhancement of dendritic cell activation via CD40 ligand-expressing gammadelta $\mathrm{T}$ cells is responsible for protective immunity to Plasmodium parasites. Proc Natl Acad Sci U S A (2012) 109(30):12129-34. doi:10.1073/pnas.1204480109

31. Pichyangkul S, Saengkrai P, Yongvanitchit K, Stewart A, Heppner DG. Activation of gammadelta T cells in malaria: interaction of cytokines and a schizontassociated Plasmodium falciparum antigen. J Infect Dis (1997) 176(1):233-41. doi:10.1086/514029
32. Singh VK, Ghosh I. Methylerythritol phosphate pathway to isoprenoids: kinetic modeling and in silico enzyme inhibitions in Plasmodium falciparum. FEBS Lett (2013) 587(17):2806-17. doi:10.1016/j.febslet.2013.06.024

33. Devilder MC, Allain S, Dousset C, Bonneville M, Scotet E. Early triggering of exclusive IFN-gamma responses of human Vgamma9Vdelta2 $\mathrm{T}$ cells by TLR-activated myeloid and plasmacytoid dendritic cells. J Immunol (2009) 183(6):3625-33. doi:10.4049/jimmunol.0901571

34. Farouk SE, Mincheva-Nilsson L, Krensky AM, Dieli F, Troye-Blomberg M. Gamma delta T cells inhibit in vitro growth of the asexual blood stages of Plasmodium falciparum by a granule exocytosis-dependent cytotoxic pathway that requires granulysin. Eur J Immunol (2004) 34(8):2248-56. Epub 2004/07/20. doi:10.1002/eji.200424861

35. Elloso MM, van der Heyde HC, vande Waa JA, Manning DD, Weidanz WP. Inhibition of Plasmodium falciparum in vitro by human gamma delta $\mathrm{T}$ cells. J Immunol (1994) 153(3):1187-94.

36. Costa G, Loizon S, Guenot M, Mocan I, Halary F, de Saint-Basile G, et al. Control of Plasmodium falciparum erythrocytic cycle: gammadelta T cells target the red blood cell- invasive merozoites. Blood (2011) 118(26):6952-62. doi:10.1182/blood-2011-08376111

37. Teirlinck AC, McCall MB, Roestenberg M, Scholzen A, Woestenenk R, de Mast $\mathrm{Q}$, et al. Longevity and composition of cellular immune responses following experimental Plasmodium falciparum malaria infection in humans. PLoS Pathog (2011) 7(12):e1002389. doi:10.1371/journal.ppat.1002389

38. Li H, Pauza CD. HIV envelope-mediated, CCR5/alpha4beta7-dependent killing of CD4- negative gammadelta $\mathrm{T}$ cells which are lost during progression to AIDS. Blood (2011) 118(22):5824-31. doi:10.1182/blood-2011-05356535

39. Lehner T, Wang Y, Whittall T, Seidl T. Innate immunity and HIV-1 infection. Adv Dent Res (2011) 23(1):19-22. doi:10.1177/0022034511399081

40. Hudspeth K, Fogli M, Correia DV, Mikulak J, Roberto A, Della Bella S, et al. Engagement of NKp30 on Vdeltal T cells induces the production of CCL3, CCL4, and CCL5 and suppresses HIV-1 replication. Blood (2012) 119(17):4013-6. doi:10.1182/blood-2011-11-390153

41. Poccia F, Battistini L, Cipriani B, Mancino G, Martini F, Gougeon ML, et al. Phosphoantigen-reactive Vgamma9Vdelta2 $\mathrm{T}$ lymphocytes suppress in vitro human immunodeficiency virus type 1 replication by cell-released antiviral factors including CC chemokines. J Infect Dis (1999) 180(3):858-61. doi:10.1086/314925

42. Hou L, Jie Z, Desai M, Liang Y, Soong L, Wang T, et al. Early IL-17 production by intrahepatic $\mathrm{T}$ cells is important for adaptive immune responses in viral hepatitis. J Immunol (2013) 190(2):621-9. doi:10.4049/jimmunol. 1201970

43. Wozniak KL, Kolls JK, Wormley FL Jr. Depletion of neutrophils in a protective model of pulmonary cryptococcosis results in increased IL-17A production by gammadelta T cells. BMC Immunol (2012) 13:65. doi:10.1186/1471-2172$13-65$

44. Pitard V, Roumanes D, Lafarge X, Couzi L, Garrigue I, Lafon ME, et al. Long-term expansion of effector/memory Vdelta2-gammadelta $\mathrm{T}$ cells is a specific blood signature of CMV infection. Blood (2008) 112(4):1317-24 doi:10.1182/blood-2008-01-136713

45. Andreu-Ballester JC, Tormo-Calandin C, Garcia-Ballesteros C, Perez-Griera J, Amigo V, Almela-Quilis A, et al. Association of gammadelta T cells with disease severity and mortality in septic patients. Clin Vaccine Immunol (2013) 20(5):738-46. doi:10.1128/cvi.00752-12

46. Chien YH, Konigshofer Y. Antigen recognition by gammadelta T cells. Immunol Rev (2007) 215:46-58. doi:10.1111/j.1600-065X.2006.00470.x

47. Gogoi D, Chiplunkar SV. Targeting gamma delta T cells for cancer immunotherapy: bench to bedside. Indian J Med Res (2013) 138(5):755-61.Epub 2014/01/18.

48. Vantourout P, Hayday A. Six-of-the-best: unique contributions of gammadelta T cells to immunology. Nat Rev Immunol (2013) 13(2):88-100. doi:10.1038/ nri3384

49. D’Asaro M, La Mendola C, Di Liberto D, Orlando V, Todaro M, Spina $\mathrm{M}$, et al. $\mathrm{V}$ gamma $9 \mathrm{~V}$ delta $2 \mathrm{~T}$ lymphocytes efficiently recognize and kill zoledronate-sensitized, imatinib-sensitive, and imatinib-resistant chronic myelogenous leukemia cells. J Immunol (2010) 184(6):3260-8. doi:10.4049/ jimmunol.0903454

50. Kabelitz D, Kalyan S, Oberg HH, Wesch D. Human Vdelta2 versus nonVdelta2 gammadelta T cells in antitumor immunity. Oncoimmunology (2013) 2(3):e23304. doi:10.4161/onci.23304 
51. Ma Y, Aymeric L, Locher C, Mattarollo SR, Delahaye NF, Pereira P, et al. Contribution of IL-17-producing gamma delta T cells to the efficacy of anticancer chemotherapy. J Exp Med (2011) 208(3):491-503. doi:10.1084/jem. 20100269

52. Wakita D, Sumida K, Iwakura Y, Nishikawa H, Ohkuri T, Chamoto K, et al. Tumor- infiltrating IL-17-producing gammadelta $\mathrm{T}$ cells support the progression of tumor by promoting angiogenesis. Eur J Immunol (2010) 40(7):1927-37. doi:10.1002/eji.200940157

53. Rei M, Goncalves-Sousa N, Lanca T, Thompson RG, Mensurado S, Balkwill FR, et al. Murine CD27(-) Vgamma6(+) gammadelta T cells producing IL-17A promote ovarian cancer growth via mobilization of protumor small peritoneal macrophages. Proc Natl Acad Sci U S A (2014) 111(34):E3562-70. doi:10.1073/pnas.1403424111

54. Rincon-Orozco B, Kunzmann V, Wrobel P, Kabelitz D, Steinle A, Herrmann T. Activation of Vgamma 9V delta $2 \mathrm{~T}$ cells by NKG2D. J Immunol (2005) 175(4):2144-51. doi:10.4049/jimmunol.175.4.2144 Epub 2005/08/06.,

55. Chen Z, Freedman MS. CD16+ gammadelta $\mathrm{T}$ cells mediate antibody dependent cellular cytotoxicity: potential mechanism in the pathogenesis of multiple sclerosis. Clin Immunol (2008) 128(2):219-27. doi:10.1016/j.clim. 2008.03.513

56. Fournie JJ, Sicard H, Poupot M, Bezombes C, Blanc A, Romagne F, et al. What lessons can be learned from gammadelta $\mathrm{T}$ cell-based cancer immunotherapy trials? Cell Mol Immunol (2013) 10(1):35-41. doi:10.1038/cmi.2012.39

57. Belmant C, Decise D, Fournie JJ. Phosphoantigens and aminobisphosphonates: new leads targeting and acquired $\gamma \delta \mathrm{T}$ lymphocytes for cancer immunotherapy. Drug Discov Today (2006) 3:17-23. doi:10.1016/j.ddstr.2006.02.001

58. Thompson K, Rogers MJ. Statins prevent bisphosphonate-induced gamma, delta-T-cell proliferation and activation in vitro. J Bone Miner Res (2004) 19(2):278-88. doi:10.1359/jbmr.0301230

59. Dieli F, Vermijlen D, Fulfaro F, Caccamo N, Meraviglia S, Cicero G, et al. Targeting human \{gamma\}delta\} $\mathrm{T}$ cells with zoledronate and interleukin-2 for immunotherapy of hormone-refractory prostate cancer. Cancer Res (2007) 67(15):7450-7. doi:10.1158/0008-5472.can-07-0199

60. Wilhelm M, Kunzmann V, Eckstein S, Reimer P, Weissinger F, Ruediger T, et al. Gammadelta T cells for immune therapy of patients with lymphoid malignancies. Blood (2003) 102(1):200-6. doi:10.1182/blood-2002-12-3665

61. Kunzmann V, Smetak M, Kimmel B, Weigang-Koehler K, Goebeler M, Birkmann J, et al. Tumor-promoting versus tumor-antagonizing roles of gammadelta $\mathrm{T}$ cells in cancer immunotherapy: results from a prospective phase I/II trial. J Immunother (2012) 35(2):205-13. doi:10.1097/CJI.0b013e318245bble

62. Gertner-Dardenne J, Bonnafous C, Bezombes C, Capietto AH, Scaglione V, Ingoure $\mathrm{S}$, et al. Bromohydrin pyrophosphate enhances antibody-dependent cell-mediated cytotoxicity induced by therapeutic antibodies. Blood (2009) 113(20):4875-84. doi:10.1182/blood-2008-08-172296

63. Shojaei H, Oberg HH, Juricke M, Marischen L, Kunz M, Mundhenke C, et al. Toll-like receptors 3 and 7 agonists enhance tumor cell lysis by human gammadelta T cells. Cancer Res (2009) 69(22):8710-7. doi:10.1158/0008-5472.can09- 1602

64. Kobayashi H, Tanaka Y, Shimmura H, Minato N, Tanabe K. Complete remission of lung metastasis following adoptive immunotherapy using activated autologous gammadelta T-cells in a patient with renal cell carcinoma. Anticancer Res (2010) 30(2):575-9.

65. Lertworapreecha M, Patumraj S, Niruthisard S, Hansasuta P, Bhattarakosol P. Cytotoxic function of gamma delta (gamma/delta) T cells against pamidronatetreated cervical cancer cells. Indian J Exp Biol (2013) 51(8):597-605.

66. Hammerich L, Tacke F. Role of gamma-delta T cells in liver inflammation and fibrosis. World J Gastrointest Pathophysiol (2014) 5(2):107-13. doi:10.4291/ wjgp.v5.i2.107

67. Oberg HH, Peipp M, Kellner C, Sebens S, Krause S, Petrick D, et al. Novel bispecific antibodies increase gammadelta $\mathrm{T}$-cell cytotoxicity against pancreatic cancer cells. Cancer Res (2014) 74(5):1349-60. doi:10.1158/0008-5472.can-130675

68. Toulon A, Breton L, Taylor KR, Tenenhaus M, Bhavsar D, Lanigan C, et al. A role for human skin- resident T cells in wound healing. J Exp Med (2009) 206(4):743-50. doi:10.1084/jem.20081787

69. Oppeltz RF, Rani M, Zhang Q, Schwacha MG. Gamma delta (gammadelta) T-cells are critical in the up-regulation of inducible nitric oxide synthase at the burn wound site. Cytokine (2012) 60(2):528-34. doi:10.1016/j.cyto.2012. 07.003
70. Rani M, Zhang Q, Schwacha MG. Burn wound gammadelta T-cells support a Th2 and Th17 immune response. J Burn Care Res (2014) 35(1):46-53. doi:10.1097/01.bcr.0000440705.91099.cc

71. Havran WL, Jameson JM. Epidermal T cells and wound healing. J Immunol (2010) 184(10):5423-8. doi:10.4049/jimmunol.0902733

72. Jameson J, Ugarte K, Chen N, Yachi P, Fuchs E, Boismenu R, et al. A role for skin gammadelta T cells in wound repair. Science (2002) 296(5568):747-9. doi:10.1126/science.1069639

73. Sharp LL, Jameson JM, Cauvi G, Havran WL. Dendritic epidermal T cells regulate skin homeostasis through local production of insulin-like growth factor 1. Nat Immunol (2005) 6(1):73-9. doi:10.1038/ni1152

74. Mills RE, Taylor KR, Podshivalova K, McKay DB, Jameson JM. Defects in skin gamma delta $\mathrm{T}$ cell function contribute to delayed wound repair in rapamycintreated mice. J Immunol (2008) 181(6):3974-83. doi:10.4049/jimmunol.181.6. 3974

75. Girardi M, Sherling MA, Filler RB, Shires J, Theodoridis E, Hayday AC, et al. Anti- inflammatory effects in the skin of thymosin-beta4 splice-variants. Immunology (2003) 109(1):1-7. doi:10.1046/j.1365-2567.2003.01616.x

76. Pennington DJ, Vermijlen D, Wise EL, Clarke SL, Tigelaar RE, Hayday AC. The integration of conventional and unconventional T cells that characterizes cell-mediated responses. Adv Immunol (2005) 87:27-59. doi:10.1016/s00652776(05)87002-6

77. Whang MI, Guerra N, Raulet DH. Costimulation of dendritic epidermal gammadelta T cells by a new NKG2D ligand expressed specifically in the skin. $J$ Immunol (2009) 182(8):4557-64. doi:10.4049/jimmunol.0802439

78. Verdino P, Witherden DA, Havran WL, Wilson IA. The molecular interaction of CAR and JAML recruits the central cell signal transducer PI3K. Science (2010) 329(5996):1210-4. doi:10.1126/science.1187996

79. Verdino P, Witherden DA, Ferguson MS, Corper AL, Schiefner A, Havran WL, et al. Molecular insights into gammadelta $\mathrm{T}$ cell costimulation by an anti-JAML antibody. Structure (2011) 19(1):80-9. doi:10.1016/j.str.2010.10.007

80. Witherden DA, Watanabe M, Garijo O, Rieder SE, Sarkisyan G, Cronin $\mathrm{SJ}$, et al. The CD100 receptor interacts with its plexin B2 ligand to regulate epidermal gammadelta T cell function. Immunity (2012) 37(2):314-25. doi:10.1016/j.immuni.2012.05.026

81. Rani M, Zhang Q, Schwacha MG. Gamma delta T cells regulate wound myeloid cell activity after burn. Shock (2014) 42(2):133-41. doi:10.1097/shk. 0000000000000176

82. Chen Y, Chou K, Fuchs E, Havran WL, Boismenu R. Protection of the intestinal mucosa by intraepithelial gamma delta T cells. Proc Natl Acad Sci U S A (2002) 99(22):14338-43. doi:10.1073/pnas.212290499

83. Pociask DA, Chen K, Choi SM, Oury TD, Steele C, Kolls JK. Gammadelta T cells attenuate bleomycin-induced fibrosis through the production of CXCL10. Am J Pathol (2011) 178(3):1167-76. doi:10.1016/j.ajpath.2010.11.055

84. Li Z, Burns AR, Rumbaut RE, Smith CW. Gamma delta T cells are necessary for platelet and neutrophil accumulation in limbal vessels and efficient epithelial repair after corneal abrasion. Am J Pathol (2007) 171(3):838-45. doi:10.2353/ajpath.2007.070008

85. Braun RK, Ferrick C, Neubauer P, Sjoding M, Sterner-Kock A, Kock M, et al. IL-17 producing gammadelta $\mathrm{T}$ cells are required for a controlled inflammatory response after bleomycin- induced lung injury. Inflammation (2008) 31(3):167-79. doi:10.1007/s10753-008-9062-6

86. Li Z, Burns AR, Miller SB, Smith CW. CCL20, gammadelta T cells, and IL-22 in corneal epithelial healing. FASEB J (2011) 25(8):2659-68. doi:10.1096/fj.11184804

87. Li Z, Burns AR, Han L, Rumbaut RE, Smith CW. IL-17 and VEGF are necessary for efficient corneal nerve regeneration. Am J Pathol (2011) 178(3):1106-16. doi:10.1016/j.ajpath.2010.12.001

88. Bendersky A, Marcu-Malina V, Berkun Y, Gerstein M, Nagar M, Goldstein I, et al. Cellular interactions of synovial fluid gammadelta $\mathrm{T}$ cells in juvenile idiopathic arthritis. J Immunol (2012) 188(9):4349-59. doi:10.4049/jimmunol. 1102403

89. Andreu-Ballester JC, Amigo-Garcia V, Catalan-Serra I, Gil-Borras R, Ballester F, Almela-Quilis A, et al. Deficit of gammadelta T lymphocytes in the peripheral blood of patients with Crohn's disease. Dig Dis Sci (2011) 56(9):2613-22. doi:10.1007/s10620-011-1636-8

90. Fletcher JM, Lalor SJ, Sweeney CM, Tubridy N, Mills KH. T cells in multiple sclerosis and experimental autoimmune encephalomyelitis. Clin Exp Immunol (2010) 162(1):1-11. doi:10.1111/j.1365-2249.2010.04143.x 
91. Markle JG, Mortin-Toth S, Wong AS, Geng L, Hayday A, Danska JS. Gammadelta $\mathrm{T}$ cells are essential effectors of type 1 diabetes in the nonobese diabetic mouse model. J Immunol (2013) 190(11):5392-401. doi:10.4049/jimmunol. 1203502

92. Bruder J, Siewert K, Obermeier B, Malotka J, Scheinert P, Kellermann J, et al. Target specificity of an autoreactive pathogenic human gammadelta- $\mathrm{T}$ cell receptor in myositis. J Biol Chem (2012) 287(25):20986-95. doi:10.1074/jbc. M112.356709

93. Accardo-Palumbo A, Giardina AR, Ciccia F, Ferrante A, Principato A, Impastato $\mathrm{R}$, et al. Phenotype and functional changes of Vgamma9/Vdelta2 T lymphocytes in Behcet's disease and the effect of infliximab on Vgamma9/Vdelta2 T cell expansion, activation and cytotoxicity. Arthritis Res Ther (2010) 12(3):R109. doi:10.1186/ar3043

94. Cai Y, Fleming C, Yan J. Dermal gammadelta T cells - a new player in the pathogenesis of psoriasis. Int Immunopharmacol (2013) 16(3):388-91. doi:10.1016/j.intimp.2013.02.018

95. Mabuchi T, Singh TP, Takekoshi T, Jia GF, Wu X, Kao MC, et al. CCR6 is required for epidermal trafficking of gammadelta-T cells in an IL-23-induced model of psoriasiform dermatitis. J Invest Dermatol (2013) 133(1):164-71. doi:10.1038/jid.2012.260

96. Yang X, Zheng SG. Interleukin-22: a likely target for treatment of autoimmune diseases. Autoimmun Rev (2014) 13(6):615-20. doi:10.1016/j.autrev.2013.11. 008

97. Hedrick MN, Lonsdorf AS, Shirakawa AK, Richard Lee CC, Liao F, Singh SP, et al. CCR6 is required for IL-23-induced psoriasis-like inflammation in mice. J Clin Invest (2009) 119(8):2317-29. doi:10.1172/JCI37378

98. Ness-Schwickerath KJ, Jin C, Morita CT. Cytokine requirements for the differentiation and expansion of IL-17A- and IL-22-producing human Vgamma2Vdelta2 T cells. J Immunol (2010) 184(12):7268-80. doi:10.4049/ jimmunol.1000600

99. Laggner U, Di Meglio P, Perera GK, Hundhausen C, Lacy KE, Ali N, et al. Identification of a novel proinflammatory human skin-homing Vgamma9Vdelta2 T cell subset with a potential role in psoriasis. J Immunol (2011) 187(5):2783-93. doi:10.4049/jimmunol.1100804

100. Hu C, Qian L, Miao Y, Huang Q, Miao P, Wang P, et al. Antigen-presenting effects of effector memory Vgamma9Vdelta2 $\mathrm{T}$ cells in rheumatoid arthritis. Cell Mol Immunol (2012) 9(3):245-54. doi:10.1038/cmi.2011.50

101. Li X, Kang N, Zhang X, Dong X, Wei W, Cui L, et al. Generation of human regulatory gammadelta $\mathrm{T}$ cells by TCRgammadelta stimulation in the presence of TGF-beta and their involvement in the pathogenesis of systemic lupus erythematosus. J Immunol (2011) 186(12):6693-700. doi:10.4049/jimmunol. 1002776

102. Li D, Wang L, Fan Y, Song L, Guo C, Zhu F, et al. Down-regulation of A20 mRNA expression in peripheral blood mononuclear cells from patients with systemic lupus erythematosus. J Clin Immunol (2012) 32(6):1287-91. doi:10.1007/s10875-012-9764-2

103. Gorczynski RM, Chen Z, Hoang Y, Rossi-Bergman B. A subset of gamma delta T-cell receptor- positive cells produce T-helper type- 2 cytokines and regulate mouse skin graft rejection following portal venous pretransplant preimmunization. Immunology (1996) 87(3):381-9. doi:10.1046/j.1365-2567.1996. 481554.x

104. Puig-Pey I, Bohne F, Benitez C, Lopez M, Martinez-Llordella M, Oppenheimer F, et al. Characterization of gammadelta $\mathrm{T}$ cell subsets in organ transplantation. Transpl Int (2010) 23(10):1045-55. doi:10.1111/j.1432-2277.2010. 01095.x
105. Latha TS, Panati K, Gowd DS, Reddy MC, Lomada D. Ovarian cancer biology and immunotherapy. Int Rev Immunol (2014) 33(5):428-40. doi:10.3109/ 08830185.2014.921161

106. Wang H, Sarikonda G, Puan KJ, Tanaka Y, Feng J, Giner JL, et al. Indirect stimulation of human Vgamma2Vdelta2 $\mathrm{T}$ cells through alterations in isoprenoid metabolism. J Immunol (2011) 187(10):5099-113. doi:10.4049/ jimmunol.1002697

107. Kabelitz D. Small molecules for the activation of human gammadelta $\mathrm{T}$ cell responses against infection. Recent Pat Antiinfect Drug Discov (2008) 3(1):1-9. doi:10.2174/157489108783413218

108. Lamb LS Jr, Bowersock J, Dasgupta A, Gillespie GY, Su Y, Johnson A, et al. Engineered drug resistant gammadelta $\mathrm{T}$ cells kill glioblastoma cell lines during a chemotherapy challenge: a strategy for combining chemo- and immunotherapy. PLoS One (2013) 8(1):e51805. doi:10.1371/journal.pone.0051805

109. Kobayashi H, Tanaka Y, Yagi J, Minato N, Tanabe K. Phase I/II study of adoptive transfer of gammadelta $\mathrm{T}$ cells in combination with zoledronic acid and IL-2 to patients with advanced renal cell carcinoma. Cancer Immunol Immunother (2011) 60(8):1075-84. doi:10.1007/s00262-011-1021-7

110. Li H, Chaudhry S, Poonia B, Shao Y, Pauza CD. Depletion and dysfunction of Vgamma2Vdelta2 T cells in HIV disease: mechanisms, impacts and therapeutic implications. Cell Mol Immunol (2013) 10(1):42-9. doi:10.1038/cmi. 2012.50

111. Rajoriya N, Fergusson JR, Leithead J, Klenerman P. Gamma delta Tlymphocytes in hepatitis C and chronic liver disease. Front Immunol (2014) 5:400. doi:10.3389/fimmu.2014.00400

112. Ma Y, Mattarollo SR, Adjemian S, Yang H, Aymeric L, Hannani D, et al. CCL2/CCR2- dependent recruitment of functional antigen-presenting cells into tumors upon chemotherapy. Cancer Res (2014) 74(2):436-45. doi:10. 1158/0008-5472.can-13-1265

113. Dar AA, Patil RS, Chiplunkar SV. Insights into the relationship between toll like receptors and gamma delta T cell responses. Front Immunol (2014) 5:366. doi:10.3389/fimmu.2014.00366

114. Niu FY, Wu YL. Novel agents and strategies for overcoming EGFR TKIs resistance. Exp Hematol Oncol (2014) 3(1):2. doi:10.1186/2162-3619-3-2

115. Fisher JP, Heuijerjans J, Yan M, Gustafsson K, Anderson J. Gammadelta T cells for cancer immunotherapy: a systematic review of clinical trials. Oncoimmunology (2014) 3(1):e27572. doi:10.4161/onci.27572

Conflict of Interest Statement: The authors declare that the research was conducted in the absence of any commercial or financial relationships that could be construed as a potential conflict of interest.

Received: 12 September 2014; accepted: 24 October 2014; published online: 10 November 2014.

Citation: Latha TS, Reddy MC, Durbaka PVR, Rachamallu A, Pallu R and Lomada D (2014) $\gamma \delta$ T cell-mediated immune responses in disease and therapy. Front. Immunol. 5:571. doi: 10.3389/fimmu.2014.00571

This article was submitted to T Cell Biology, a section of the journal Frontiers in Immunology.

Copyright (c) 2014 Latha, Reddy, Durbaka, Rachamallu, Pallu and Lomada. This is an open-access article distributed under the terms of the Creative Commons Attribution License (CC BY). The use, distribution or reproduction in other forums is permitted, provided the original author(s) or licensor are credited and that the original publication in this journal is cited, in accordance with accepted academic practice. No use, distribution or reproduction is permitted which does not comply with these terms. 